\title{
Do funccionamento renal na febre amarella, na convalescença e após a cura
}

\author{
Por J. CASTRO TEIXEIRA (do Hospital Oswaldo Cruz)
}

Durante o surto de Febre Amarella, no segundo semestre de 1928, praticámos algumas provas de funccionamento renal em doentes internados no Hospital Oswaldo Cruz, sendo 4 casos na convalescença e 5 após a cura da molestia.

Para mais facil interpretação, reunimos os nossos resultados em graphicos e os illustrámos com as curvas de temperatura, pulso e tensão arterial (methodo auscultatorio). Relacionámos os dias de prova com o regimem alimentar e o dia de molestia,

\section{METHODOS EMPREGADOS}

Prova de diluição e de concentração: empregámos o methodo de VIOLLE combinado com o de VOLHARD. Estando o doente em jejum e em equilibrio chloretado, administram-se 800 c.c. de agua ou chá, em fracçб̃es de 200 c.c. de meia em meia hora, a partir de 8 horas, momento em que se faz o doente urinar. Em seguida colhem-se as urinas de meia em meia hora até ás 11 horas, verificando em cada porção o volume e a densidade. E tambem pelo resto do dia, em tempo mais espaçado, isto é, ás 13,17 , 20 e 8 horas do dia seguinte, e o doente fica em dieta secca.

Prova de chloretos e de uréa: Procura-se antes um equilibrio chloretado e azotado e submette-se o doente ao mesmo regimem alimentar durante os dias de prova. A dieta $3 a$ a que se referem os graphicos é achloretada; a 4 a hypoazotada e a 5 a normal. No 10 dia de prova, o doente urina ás 8 horas e despreza-se esta micção; depois, urina ás $10,12,14,16$, 18,20 e 8 horas do dia immediato. Constitue este o typo normal. No $2^{0}$ dia colhem-se as urinas como acima e ministram-se 10 grs. de chloreto de sodio em capsulas ou junto com os alimentos da 1a refeição, ás 11 horas. No 30 dia repete-se o typo normal e no 40 dia colhem-se as urinas como nos dias anteriores e ministram-se 20 grs. de uréa, em xarope, ás 10 horas. Em cada fracção de urina, medem-se volume e densidade, dozam-se os chloretos e a uréa, pesquiza-se albumina e pratica-se o exame microscopico.

Prova colorimetrica: Empregámos a prova da phenolsulfophtaleina, em injecção intramuscular de $0,005 \mathrm{gr}$. e dosámos a eliminação pelo colorimetro de HELLIGE.

Prova de hydrophilia: Technica de ALDRICH e MC CLUREL: injecção intradermica, na perna, de 0,25 c.c. de solução de $\mathrm{NaCl} 0,85 \%$.

Os doentes observados na convalescença, 3 casos, (graphicos 1, 2 e 4) foram de forma benigna e de signaes renaes pouco notaveis. Houve 1 caso grave (graphico 3) em que foi sensivel o ataque ao rim, existindo 
na urina, por muitos dias, grande quantidade de albumina e abundancia de cylindros, principalmente granulosos, e cellulas renaes.

O graphico n. 1 mostra uma má eliminação de agua, incapacidade de diluição, capacidade de concentração e eliminação satisfactoria do chloreto e da uréa de próva. A próva de ALDRICH e MC CLUREL revelou uma tendencia dos tecidos á hydrophilia.

O graphico n. 2 indica um retardamento na eliminação da agua, regular capacidade de diluição, capacidade de concentração e eliminação quasi total do chloreto e da uréa de prova.

Graphico n. 3. As provas foram feitas na convalescença, que foi muito prolongada e, como vimos, o rim foi muito atacado. Revela uma má eliminação dagua, capacidade de diluição e de concentração, má eliminação do chloreto e da uréa de prova.

Graphico n. 4. Retardamento na eliminação da agua, boa capacidade de diluição de concentração, eliminação completa do chloreto e da uréa de próva. A próva de ALDRICH e MC CLUREL foi de 46 minutos.

Os doentes estudados após cura (graphicos ns. 5, 6, 7, 8 e 9) foram de formas mais graves e nelles o exame da urina revelou, por muitos dias, grande quantidade de albumina, abundancia de cylindros granulosos e epitheliaes e cellulas renaes, principalmente no doente do graphico n. 8 .

A eliminação da agua foi normal, os rins mostraram capacidade de diluição e de concentração, menos no caso n. 8 em que estas funcções estiveram diminuidas e aquella retardada.

A uréa de próva fui eliminada e quanto ao chloreto de próva houve retenção quasi total em 2 casos (graphicos 5 e 8).

\section{CONCLUSÕES}

1) Os doentes observados na convalescença eram, na sua maior parte, da fórma benigna.

2) Os doentes observados após a cura eram casos da fórma grave.

3) $\mathrm{Na}$ convalescença as próvas para o funccionamente renal revelaram um retardamento na eliminação da agua, perturbação na diluição e capacidade de concentração. Eliminação boa do chloreto e da uréa de próva.

4) Após a cura, pelas próvas feitas, verificámos que os rins eliminam normalmente a agua, tem capacidade de diluição e de concentração e eliminam o chloreto e a uréa de próva.

5) A próva de ALDRICH e MC CLUREL, feita em 4 casos, revelou uma pequena tendencia dos tecidos á hydrophilia.

\begin{tabular}{|c|c|c|c|c|c|}
\hline Graphicos & 1 & 3 & 8 & 4 & Normal \\
\hline Test & $46^{\prime}$ & $37^{\prime}$ & $45^{\prime}$ & $46^{\prime}$ & $60^{\prime}$ \\
\hline
\end{tabular}

6) A prova de phenolsulfophtaleina, na convalescença, deu uma eliminação, em media, de $45,2 \%$, na 1 a hora. 


\begin{tabular}{|c|c|c|c|c|c|}
\hline Graphico & 1 & 2 & 3 & 4 & Normal \\
\hline $\begin{array}{c}\text { Eliminação } \\
\text { 1a h. }\end{array}$ & $47 \%$ & $42 \%$ & $40 \%$ & $52 \%$ & $65 \%$ \\
\hline
\end{tabular}

7) Pela prova da phenolsulfophtaleiıa, após a cura, verificárnos uma eliminação, em media, de $65 \%$, na 1 a hora.

\begin{tabular}{|c|c|c|c|c|}
\hline Graphico & 9 & 8 & 6 & Normal \\
\hline Eliminação $1 \mathrm{a}$ h. & $57 \% \%$ & $70 \%$ & $68 \%$ & $65 \%$ \\
\hline
\end{tabular}

8) Pelos resuitados obtidos, parece-nos que a reparação das funcções renaes, de diluição e concentração, de eliminação de chloreto, de uréa e da phenolsulfophtaleina sefaz rapida e completamente, na febre amarella.

\section{BIBIIOGIRA PIIIA.}

1) MC CLUREL e ALDRICH-The intradermical salt solution test, Jour. Am. Med. Ass., Maio de 1924.

2) LITHSWITZ-Enfermedades del riñon-Trad. 1926.

3) VOLHARD - Enfermedades del riñon-Trad. hespanhola 1922.

4) MARCEL LABBE' et VIOLLE - Métabolisme de l'eau. 1927.

5) PENIDO, J. C.-Supp. Memorias Inst. Oswaldo Cruz, Out. 192.8. Observações sobre alguns elementos da urina na Febre Amarella.

\section{RESUMO DAS OBSERVAÇÕES}

Graphico n. 1-A. S. C., Reg. 169 A., 22 annos, branco, portuguez. Inicio com cephalalgia, mal estar e vomitos. Ao ser internado sentia grande abatimento, olhos injectados, ictericia bem nitida da esclerotica. Baço crescido. Dôr epigastrica. Bulhas cardiacas abafadas. Exame da urina: grande quantidade de albumina, cylindros granulosos, urobilina. Até o 130 dia continuou com grande adynamia. Até o 80 dia de molestia tinha cylindros na urina, persistindo depois traços de albumina.

Graphico n. 2-S. I. Reg. 829, 10 anrios, branco, brasileiro. Adoeceu com dores musculares, fraqueza nos membros inferiores e peso na cabeça. Ao internar-se apresentava olhos brilhantes e injectado;, e vaso dilatação peripherica. Baço augmentado. Durante 3 dias teve cylindros na urina e traços de albumina.

Graphico n. 3-I. D., Reg. 853, 14 annos, branco, russo. Inicio com cephalalgia, dores lombares $e$ temperatura elevada. Ansiedade e dôres epigastricas. Vomitos de "borra de café" desde o $2^{\circ}$ dia de molestia. Grande prostração, olhos brilhantes, sub-ictericia. Exame da urina, ao entrar: Grande quantidade de albumina, cylindros granulosos e epitheliaes e cellulas renaes. O estado do doente aggravou-se até o 70 dia de molestia, tendo dias de delirio. A ictericia augmentou progressivamente. Os signaes urinarios melhoraram depois do $16^{\circ}$ dia.

Graphico n. 4--F. W., Reg. 165 A., 12 annos, branco, hungaro. Cephalalgia, fortes dores lombares, mau estar, vomitos e oppressão epigas- 


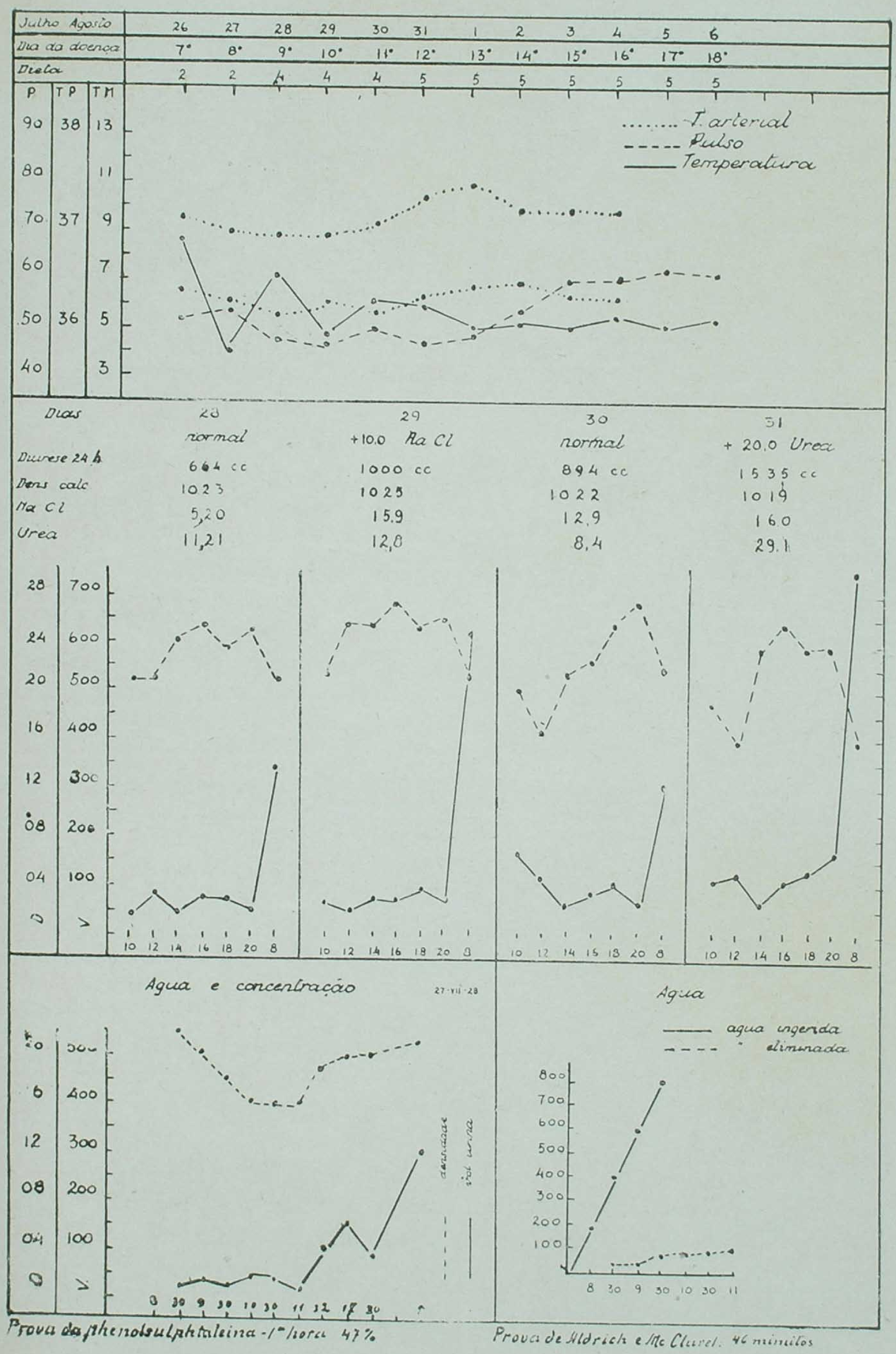

Graphico n. 1 


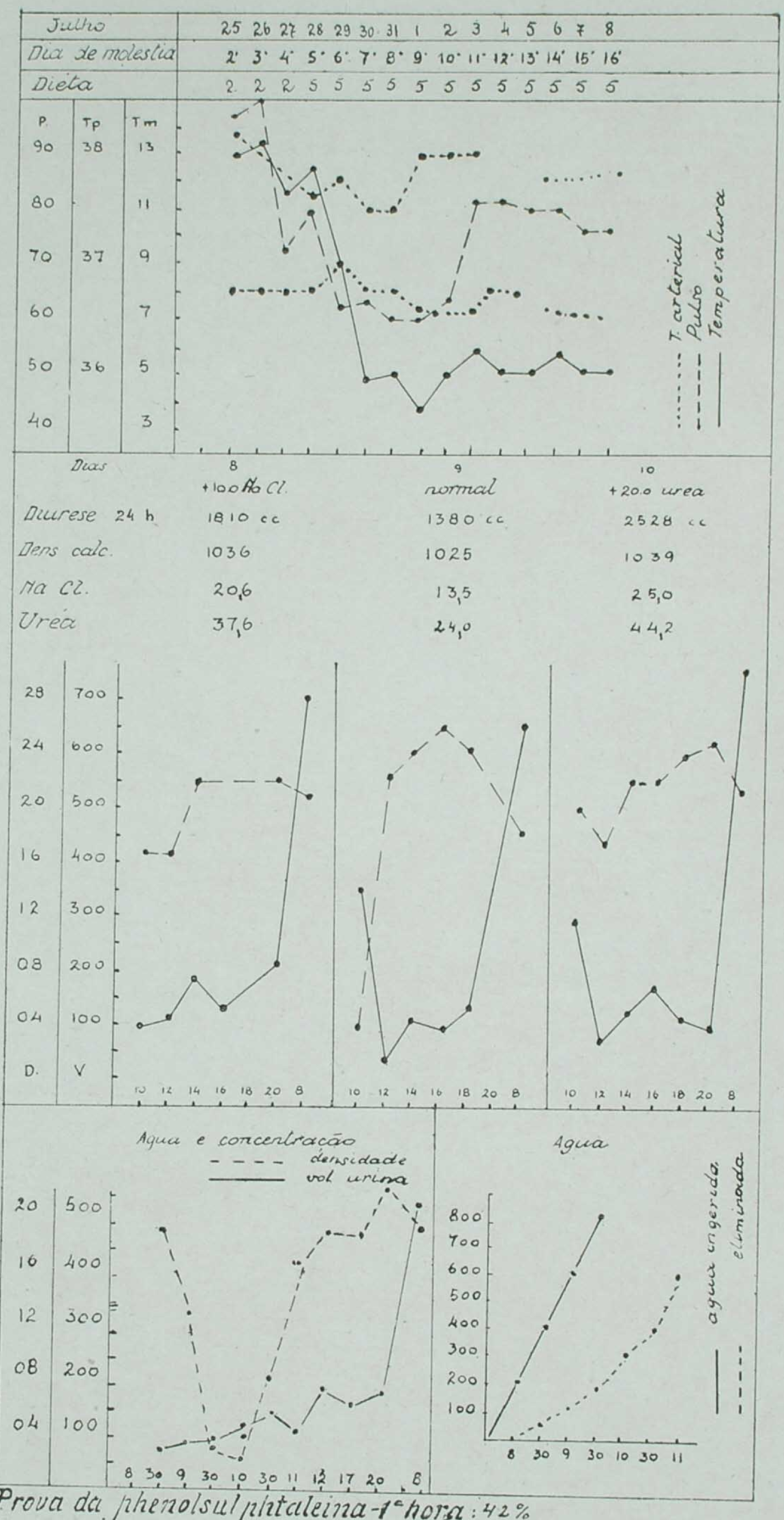

Prova da jhenolsulpintaleina-1"horas : $42 \%$

Graphico n. 2 


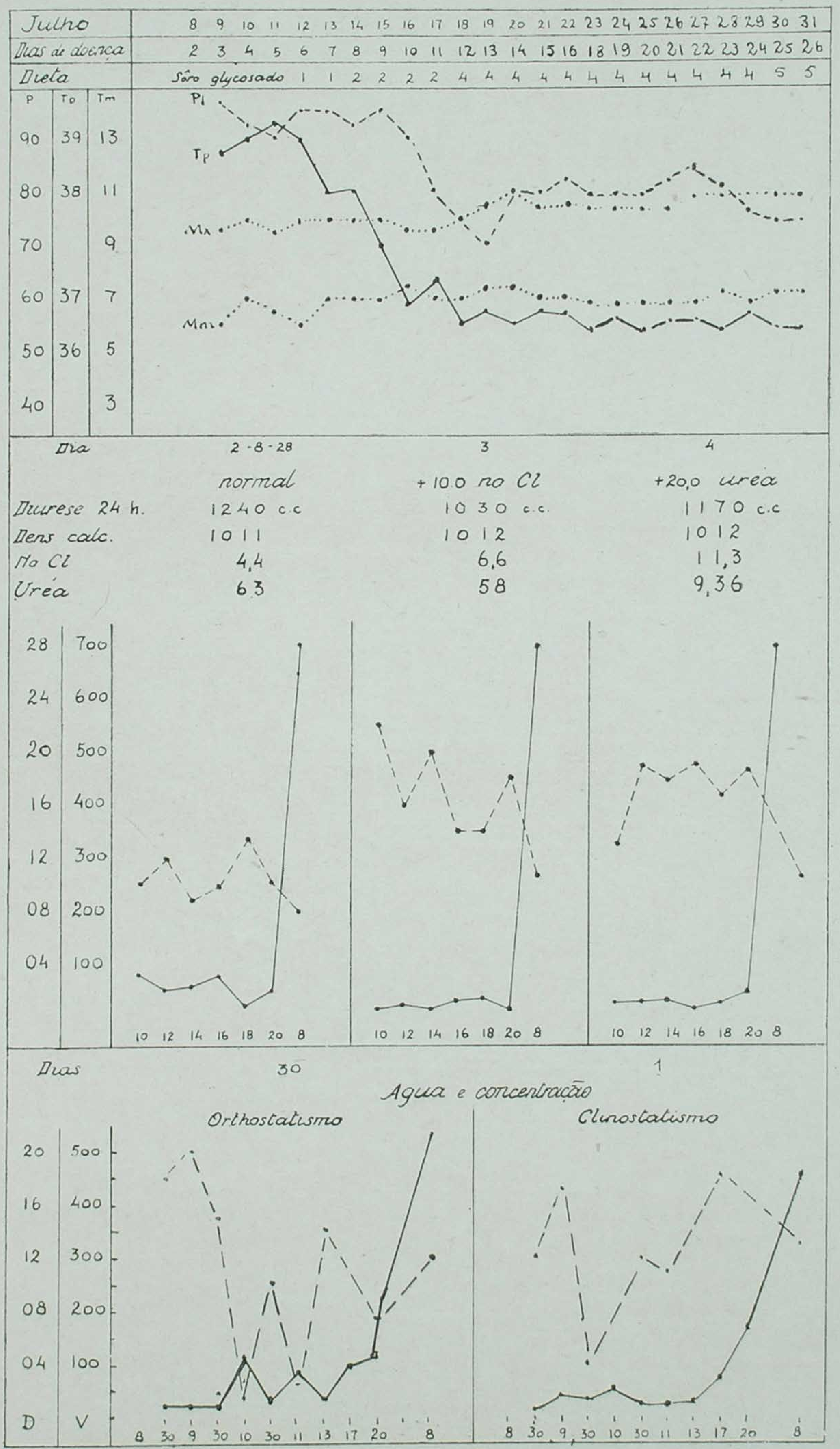

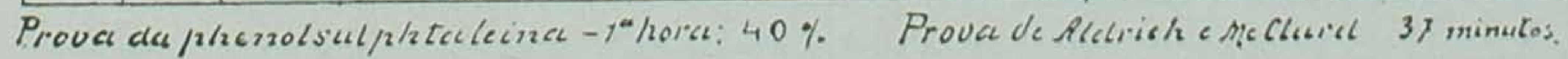

Graphico n. 3 


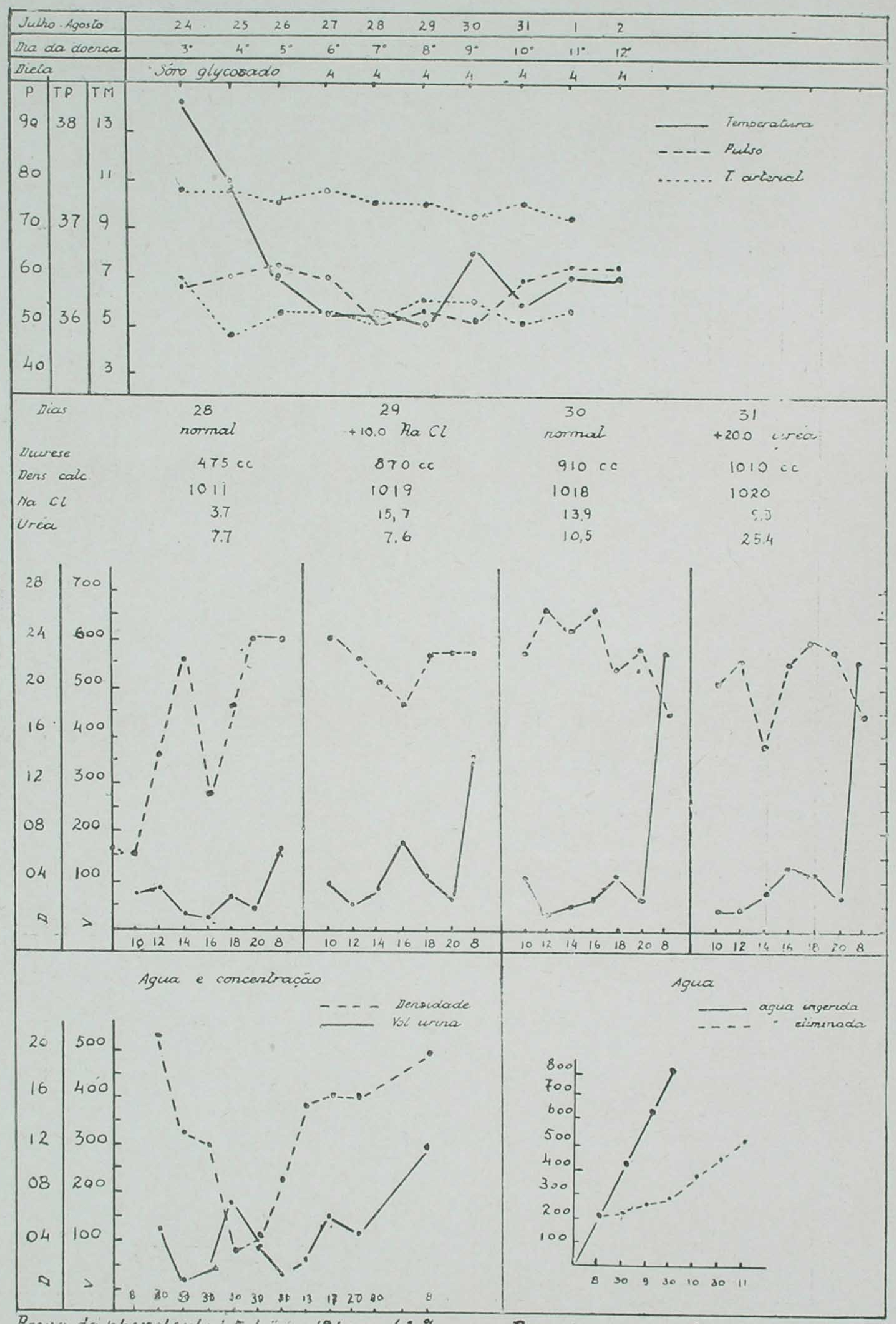

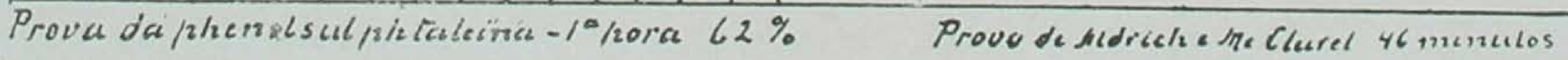

Graphico n. 4 


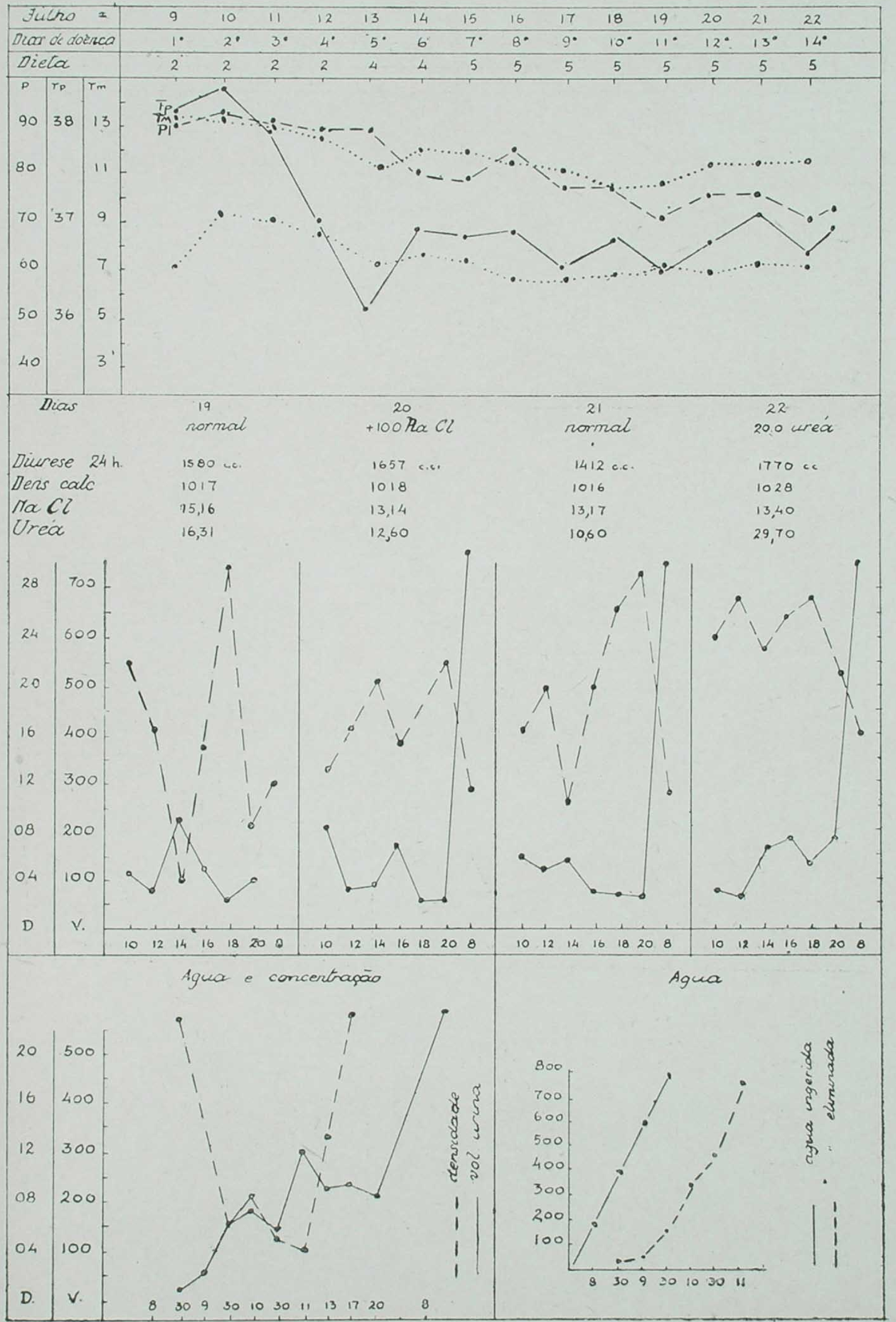

Graphico n. 5 


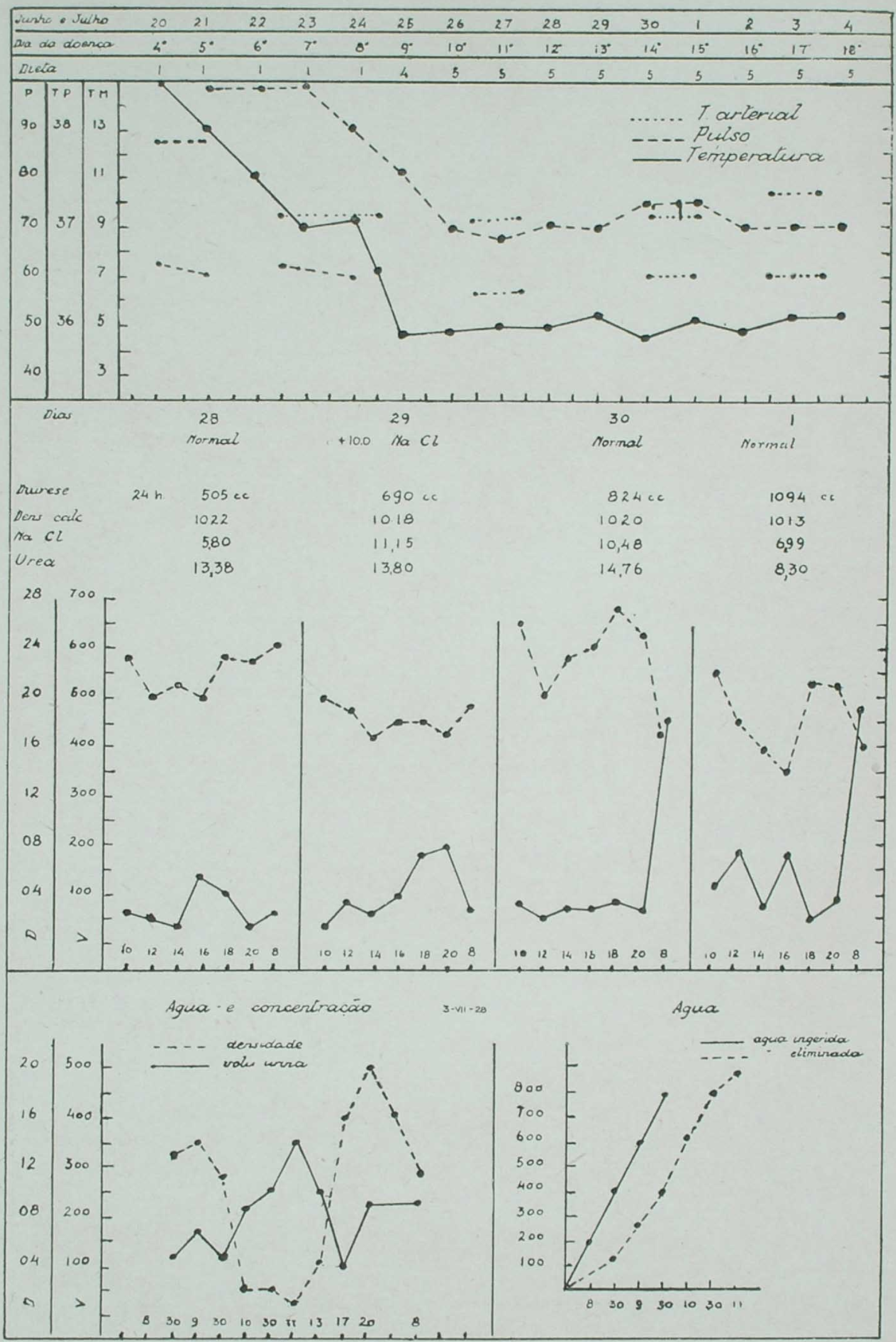

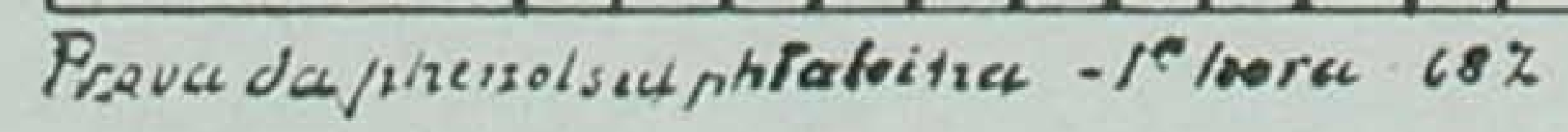




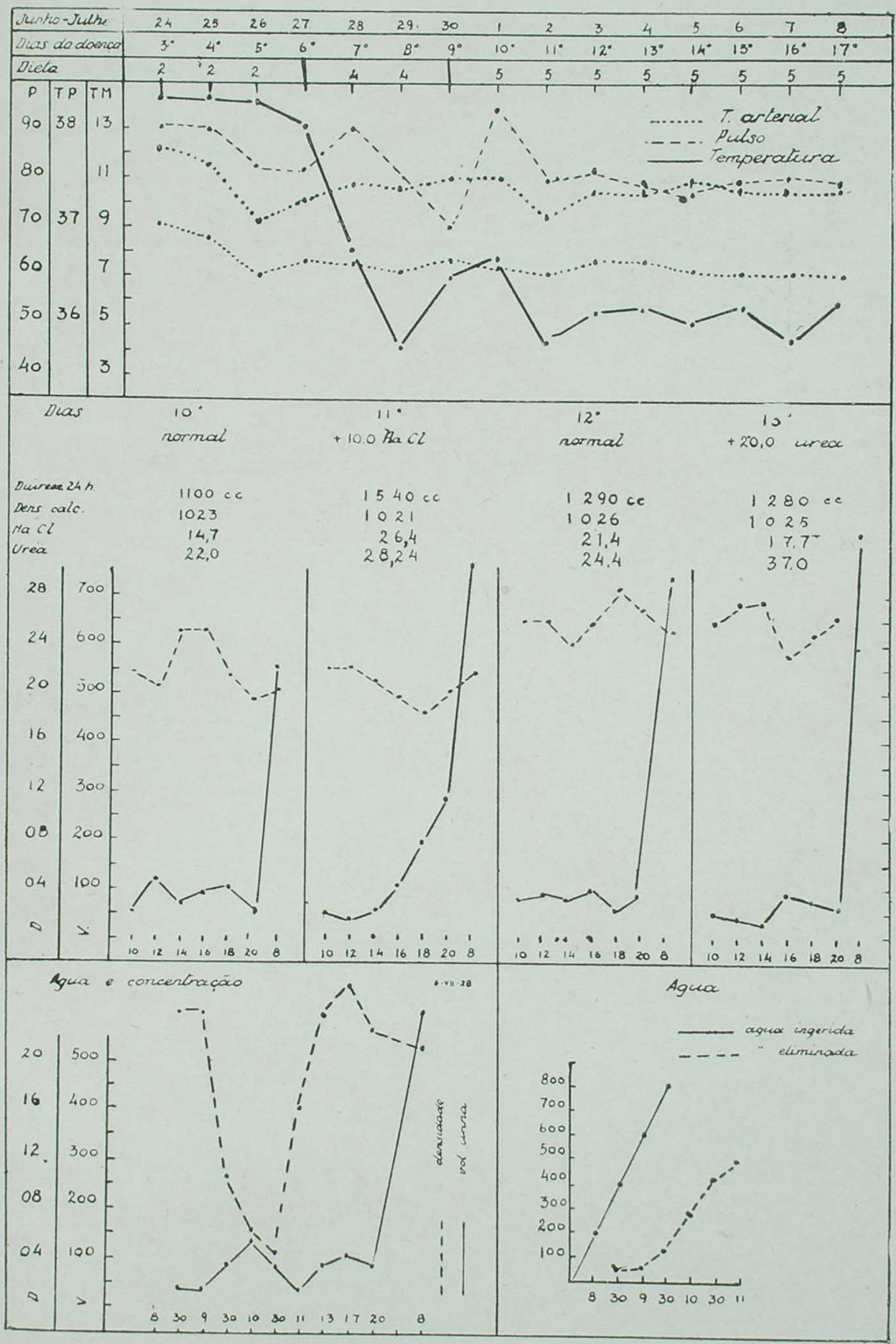

Graphico n. 7 


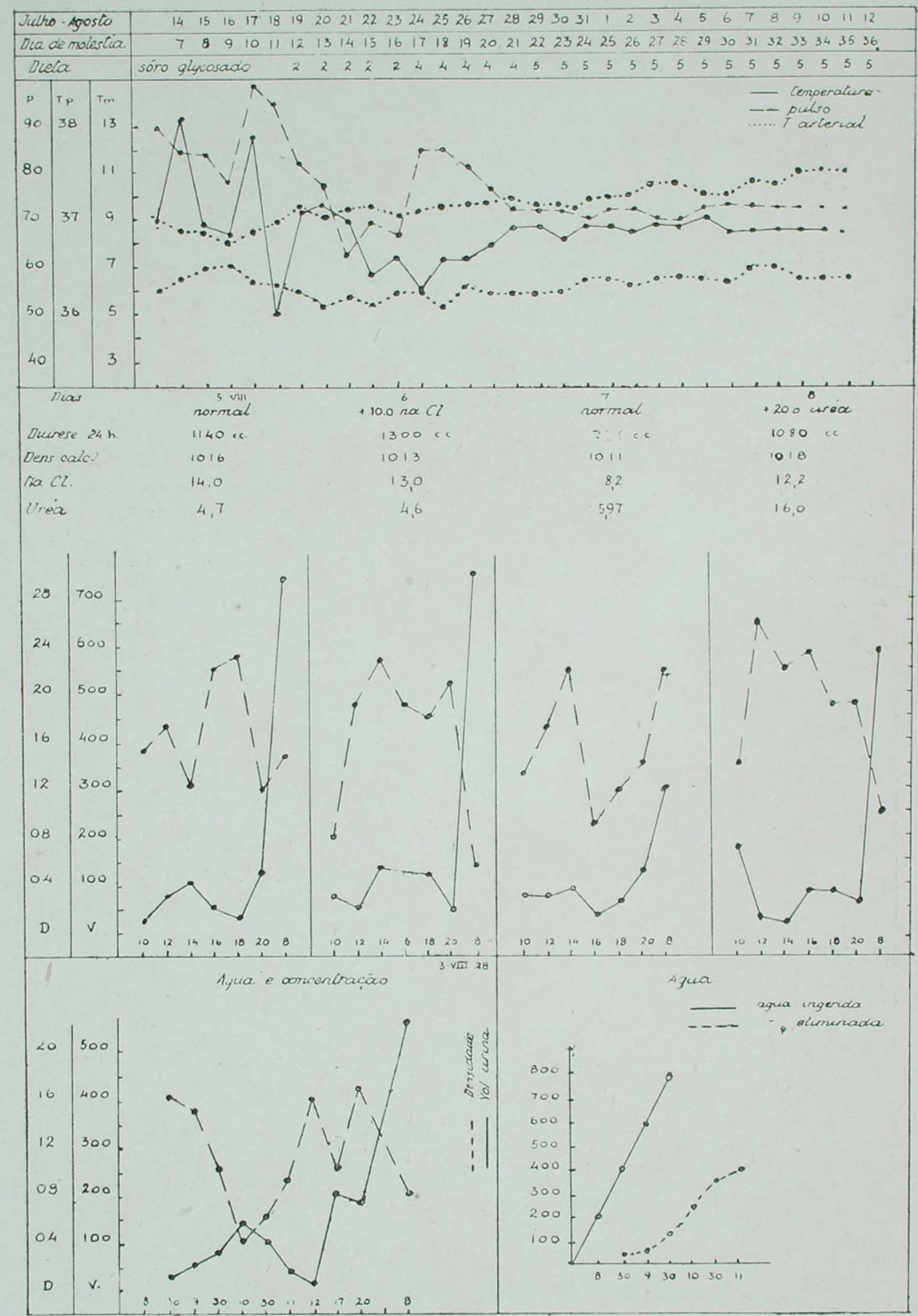

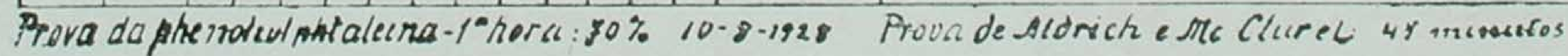

Graphico n. 8 


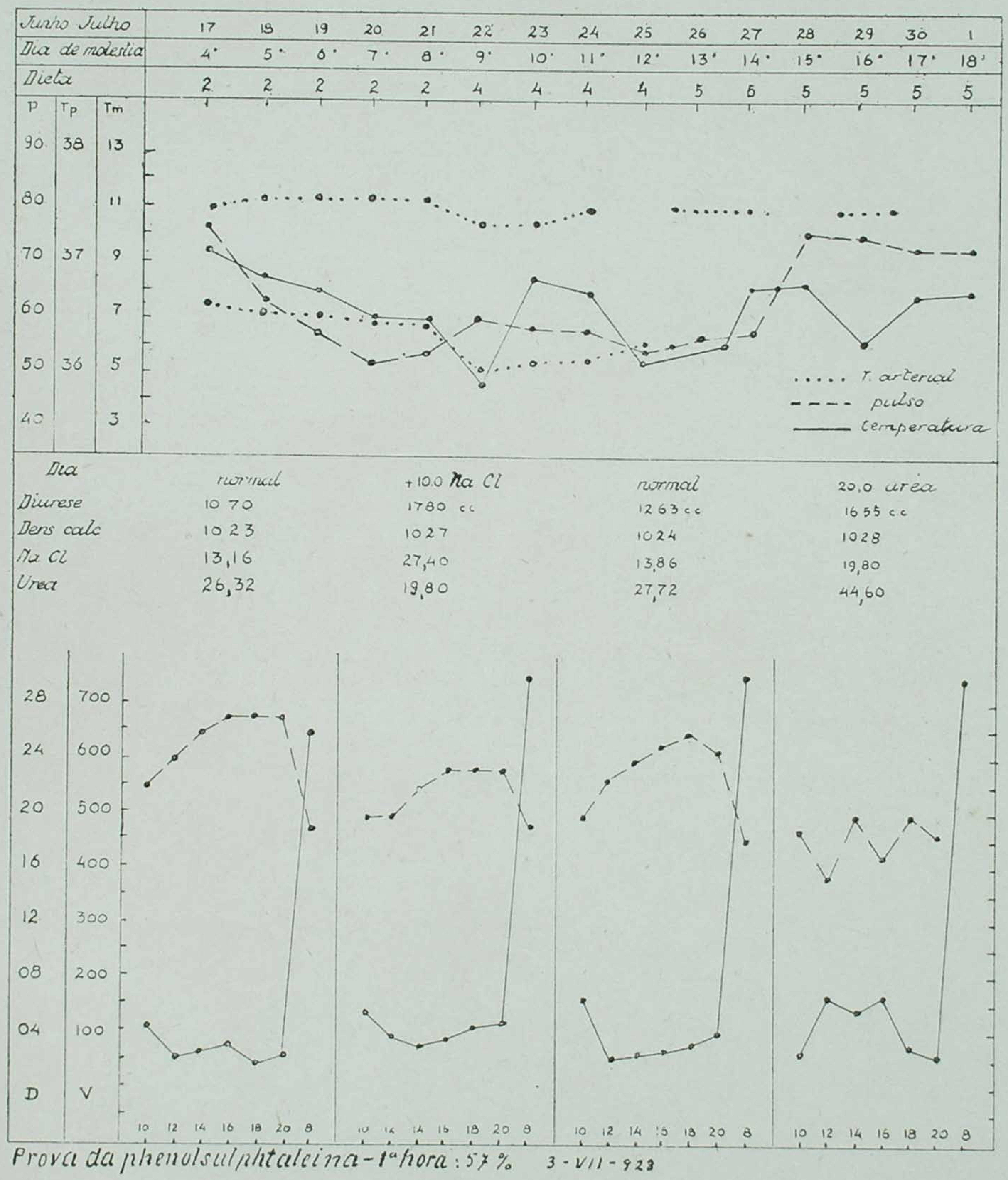

Graphico n. 9 
trica. Grande prostração, rubor da face, vaso-dilatação peripherica. Face vultuosa. Depois de internado teve vomitos pretos. Os cylindros desappareceram depois do 80 dia e a albumina no 10 .

Graphico n. 5-A. H. M., Reg. 824, 22 annos, branco, portuguez. Adoeceu com cephalalgia, dores lombares, calafrio e elevação thermica. Face vultuosa, olhos injectados. Albumina e cylindros na urina por muitos dias. Ictericia desde o 40 dia.

Graphico n. 6-Y. P., Reg. 824, 15 annos, branca, brasileira. Calafrios e elevação thermica. Cephalalgia e grande mal estar. Vomitos de "borra de café" desde o 40 dia. Nos primeiros dias os symptomas se aggravaram. Cylindruria até o 60 dia de molestia, restando traços de albumina.

Graphico n. 7-M. M., Reg. 829, 28 annos, branco, portuguez. Inicio com calafrios, febre, cephalalgia e dores lombares. Ao internar-se apresentava grande prostração, rubor da face, olhos brilhantes e injectados. Lingua humida com muita saburra. A urina revelou grande quantidade de albumina e cylindros granulosos. Os signaes renaes duraram até o $16^{\circ}$ dia. Não teve vomitos. Icterica intensa.

Graphico n. 8-A. S. S., Reg. 868, 18 annos, pardo, brasileiro. Internado em estado de confusão mental, Adynamia com grande apathia. Mucosas labiaes sangrando á pressão. Leve ictericia. Pequeno edema das palpebras. Baço palpavel. Oliguria. Grande quantidade de albumina e abundancia de cylindros granulosos e epitheliaes e cellulas renaes. Sómente depois de 100 dia de hospitalização foi que as melhoras se accentuaram e nesse dia desappareceram os cylindros. Traços de albumina.

Graphico n. 9-A. A. F., Reg. 821, 19 annos, branco portuguez. Cephalalgia, rachialgid, adynamia. Face vultuosa. Suffusøes sanguineas nos labios. As mucosas do nariz, gengivas e labios sangraram por muitos dias. Urina: grande quantidade de albumina, cylindros granulosos e epitheliaes e cellulas renaes, tendo este signaes desapparecido depois do 100 dia. Icterica muito accentuada. 